\title{
IMMUNOHISTOCHEMICAL EXPRESSION OF $\triangle$ NP63 IN ORAL CARCINOMA IN SITU AND ORAL SQUAMOUS CELL CARCINOMA IN COMPARISON WITH NORMAL ORAL EPITHELIUM.
}

\author{
Ayed Dahan*, Naglaa Al-Hossary ${ }^{* *}$ and Dalia Hussein El-Rouby ${ }^{* * *}$
}

\begin{abstract}
$\Delta \mathrm{Np} 63$ exerts dominant-negative activities against TAp63 and $\mathrm{p} 53$, and $\Delta \mathrm{Np} 63$ is thus considered as an oncoprotein. The majority of the initial alterations of precancerous and cancerous oral lesions are not readily recognizable, on clinical or histopathological examination. The basic biology of initiation and progression of these tumors is still obscure. So the objective of this study is to evaluate the expression of $\triangle \mathrm{NP} 63$ among normal oral epithelium, oral carcinoma in situ and OSCC using an immunohistochemical approach.
\end{abstract}

Material and methods: A total of 78 archival paraffin embedded specimens (26 normal oral epithelium, 26 oral carcinoma in situ and 26 OSCC) will be collected. The mean $\triangle \mathrm{NP} 63$ will be evaluated by immunohistochemical staining, $(\mathrm{P}<0.05)$ was considered statistically significant.

RESULTS: $\triangle \mathrm{Np} 63$ the greatest mean area of immunoexpression was recorded in the poorly differentiated OSCC, whereas the least value was recorded in normal mucosa. (ANOVA) test revealed that the difference was extremely statistically significant $(\mathrm{P}<0.0001)$.

CONCLUSION: The intensity of positive immunoreaction gradually increased with progression of OSCC.

\section{INTRODUCTION}

Oral cavity cancer is one of the most common neoplastic lesions of the head and neck. Squamous cell carcinoma being ranked as the sixth worldwide ${ }^{1}$. In fact, a series of several mutations to certain classes of genes is usually required before a normal cell will transform into a cancer cell. Only mutations in those certain types of genes that play vital roles in cell division, apoptosis (cell death), and DNA repair will cause a cell to lose control of its proliferation ${ }^{2}$. P63 has two different promoter domains that generate two protein isoforms, TAp63 and $\Delta \mathrm{Np} 63$; each isoform yields three isotypes $(\alpha, \beta, \gamma)$ generated by alternative splicing of the p63 COOH terminus. TAp63 includes an NH2

* B.D.S , M.D.S, Ministry of Public Health,Yemen

** Professor of Oral Pathology, Faculty of Oral and Dental Medicine, Cairo University

*** Professor and Head of Oral Pathology Department, Faculty of Oral and Dental Medicine Cairo University 
terminal transactivation domain, which is absent in $\Delta \mathrm{Np} 63^{3}$. TAp63 transactivates p53 target genes to induce apoptosis by inhibiting cell proliferation in response to exposure of cells to DNA-damaging agents such as ultraviolet irradiation. In contrast, $\Delta$ Np63 exerts dominant-negative activities against TAp63 and p53, and $\Delta N p 63$ is thus considered as an oncoprotein ${ }^{4}$. The $\Delta \mathrm{N}$ isoforms of $\mathrm{p} 63$ were initially described as unable to induce transcription, acting in a dominant negative manner either by competing for DNA binding sites or by directly binding to p53 or TA isoforms, rendering them inactive. However, it have been suggested that $\Delta \mathrm{Np} 63$ have important transcriptional activities on their own ${ }^{5} . \Delta \mathrm{Np} 63$ plays an anti-differentiation and anti-apoptotic role, a key role in the tumor genesis. $\triangle \mathrm{Np} 63$ isoforms contribute to keep a stem-like phenotype in $\mathrm{SCC}^{6}$.

\section{MATERIALS AND METHODS}

Seventy eight archival paraffin embedded specimens were retrieved from the archives of the Oral Pathology Department(Faculty of Oral \& Dental Medicine) and the Surgical Pathology Department (National Cancer Institute), Cairo University. Five $\mu \mathrm{m}$ thick sections were cut from each specimen and submitted for routine hematoxylin and eosin staining to be examined under light microscope for confirmation of the previous diagnosis.

\section{Immunohistochemistry technique:}

Formalin-fixed, paraffin-embedded tissue sections were cut at Five $\mu \mathrm{m}$ and stained using standard immunohistochemical methodology. primary antibodies was used $\boldsymbol{\Delta}$ NP63: (Novus biological, USA) is a rabbit polyclonal antihuman antibody it was prepared according to the manufacturer's instruction.

\section{Assessment Of Immunostaining:}

Ordinary Light Microscope: To detect the positive and negative immunostaining. The immunostained sections were examined using the software Leica Qwin 500 system (Leica microsystem, Switzerland). The image analyzer consists of a colored video camera, colored monitor and a personal computer connected to the microscope and controlled by Leica Qwin 500 software.

\section{RESULTS}

In Normal Oral Mucosa, the immunopositivity was seen in a patchy sporadic manner involving the nucleus and cytoplasm of the basal and suprabasal cells (Fig. a). In Oral Carcinoma in Situ, The immunopositivity was seen in the cytoplasm of the cells Positive immunoreaction for $\triangle \mathrm{NP} 63$ was noted in the nuclei of some epithelial (Fig. b).

Oral Squamous Cell Carcinoma (OSCC), Positive immunostaining was seen in all studied cases of poorly differentiated OSCC. Immunoexpression was generalized in the cytoplasm of the malignant epithelial cells invading the connective tissue. Some nuclei were positively stained. Positive immunoreaction was detected in the connective tissue stroma cells surrounding the malignant cells (Fig. c).

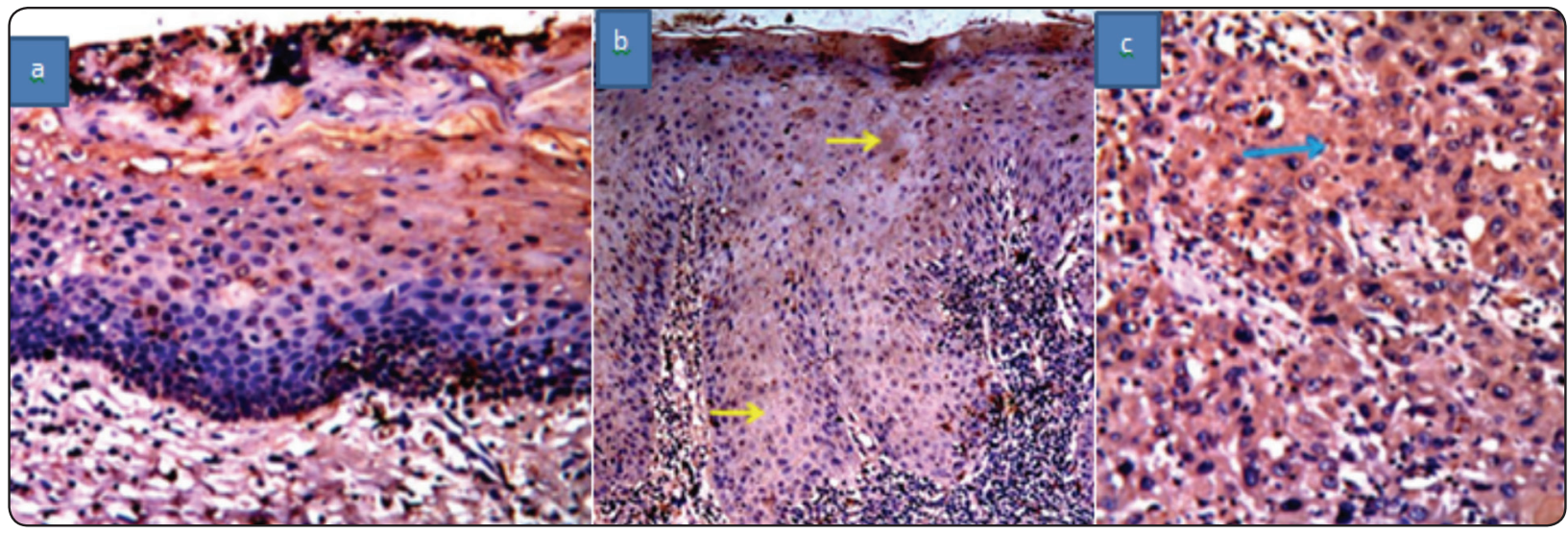




\section{Statistical analysis}

Area percent of $\triangle \mathrm{NP63}$ immunoexpresion, the greatest mean area of immunoexpression was recorded in the poorly differentiated OSCC, whereas the least value was recorded in normal mucosa. Analysis of variance (ANOVA) test revealed that the difference was extremely statistically significant $(\mathrm{P}<0.0001)$.

\section{DISCUSSION}

The results of this work demonstrated that the immunohistochemical reactivity was detected in nuclei of the basal and suparabasal layers of normal cells and severe dysplastic cells. Similar findings were detected by ${ }^{7}$, where $\Delta \mathrm{Np} 63$ immunoreaction was noted in basal and suprabasal cells of normal oral mucosa, and in the nuclei of cells in the basal layers of the normal breast and prostate epithelium. Similarly, ${ }^{8}$ reported intense p63 staining in basal, parabasal,and suprabasal cells of normal oral mucosa, with gradual decrease at the midlevel of the epithelium. Chen et al., (2005) ${ }^{9}$ also reported that p63 nuclear staining was predominantly detected in the basal layers of the epithelium and only focally in parabasal cells of the normal buccal mucosa. $\triangle \mathrm{Np} 63$ isoforms are proposed to be the most abundant isoforms of p63 in epithelial tissues ${ }^{10}$. These prominent isoforms have been shown to be expressed in basal epithelial cells in diverse epithelial organs where they are believed to be regulators of differentiation and stratification ${ }^{11}$.

In different degrees of epithelial dysplasia, Vered et al., (2009)mild dysplasia ( $\mathrm{MD}^{12}$ mild dysplasia (MD observed that the number of $\Delta \mathrm{Np} 63$ positive cells increased in association with the severity of epithelial dysplasia. The same result was obtained by Matsubara et al., (2011) ${ }^{14}$ in severe oral dysplasia. The present results showed significant progressive increase in immunoreactivity with increased grade of OSCC. In the same context, Geddert et al., $(2003)^{15}$ reported that strong expression of p63, especially of its $\Delta \mathrm{Np} 63$ (p40) isoforms, is a frequent finding in cancerous esophageal squamous lesions. Moreover, other studies found significant association between the $\Delta \mathrm{Np} 63$ positive rate and the degree of differentiation in nasopharyngeal carcinoma, lung carcinoma, and epidermal carcinoma ${ }^{16}$.

\section{REFERENCES}

1. Marklund, L. et al. Prevalence of human papillomavirus and survival in oropharyngeal cancer other than tonsil or base of tongue cancer. Cancer Med. 1, 82-8 (2012).

2. Croce, C. M. Oncogenes and cancer. N. Engl. J. Med. 358, 502-11 (2008).

3. Hagiwara, K., Mcmenamin, M. G., Miura, K. \& Harris, C. C. Advances in Brief Mutational Analysis of the p63 / p73L / p51 / p40 / CUSP / KET Gene in Human Cancer Cell Lines Using Intronic Primers. 4165-4169 (1999).

4. Mills, A. a. P63: Oncogene or Tumor Suppressor? Curr. Opin. Genet. Dev. 16, 38-44 (2006).

5. Mckeon, F. p63 and the epithelial stem cell : more than status quo ? 465-469 (2004).

6. Rp, D. et al. CUSP / p63 expression in basal cell carcinoma. 203-208 (2002).

7. Nylander, K. et al. Differential expression of p63 isoforms in normal tissues and neoplastic cells. J. Pathol. 198, 41727 (2002).

8. Bortoluzzi, M. C., Yurgel, L. S., Dekker, N. P., Jordan, R. C. K. \& Regezi, J. A. Assessment of p63 expression in oral squamous cell carcinomas and dysplasias. Oral Surg. Oral Med. Oral Pathol. Oral Radiol. Endod. 98, 698-704 (2004).

9. Chen, Y., Hsue, S. \& Lin, L. Expression of p63 protein and mRNA in oral epithelial dysplasia. 232-239 (2005).

10. Parsa, R., Yang,A., Mckeon, F. \& Green, H. Association of p63 with Proliferative Potential in Normal and Neoplastic Human Keratinocytes. 1099-1105 (1999).

11. Candi, E. et al. p63 in epithelial development. Cell. Mol. Life Sci. 65, 3126-33 (2008).

12. Vered, M., Allon, I. \& Dayan, D. Maspin, p53, p63, and $\mathrm{Ki}-67$ in epithelial lesions of the tongue: from hyperplasia through dysplasia to carcinoma. J. Oral Pathol. Med. 38, 314-20 (2009).

13. Matsubara, $R$. et al. Increased $\Delta N p 63$ expression is predictive of malignant transformation in oral epithelial dysplasia and poor prognosis in oral squamous cell carcinoma. Int. J. Oncol. 39, 1391-9 (2011). 
14. Matsubara, R. et al. Increased $\triangle \mathrm{Np} 63$ expression is predictive of malignant transformation in oral epithelial dysplasia and poor prognosis in oral squamous cell carcinoma. Int. J. Oncol. 39, 1391-1399 (2011).

15. Geddert, H., Kiel, S., Heep, H. J., Gabbert, H. E. \& Sarbia, $\mathrm{M}$. The role of p63 and $\Delta \mathrm{Np} 63$ (p40) protein expression and gene amplification in esophageal carcinogenesis. Hum. Pathol. 34, 850-856 (2003).

16. Crook, T., Nicholls, J. M., Brooks, L., Nions, J. O. \& Allday, M. J. High level expression of D N-p63 : a mechanism for the inactivation of $\mathrm{p} 53$ in undi erentiated nasopharyngeal carcinoma ( NPC )? 53, 0-5 (2000). 